\title{
Suspensão Cautelar e CanCelamento DE REGISTRO DE MEDICAMENTOS: GARANTIAS CONSTITUCIONAIS AO DIREITO À SAÚDE
}

\author{
PROVISIONAL REMEDIES AND REGISTER'S CANCELLATION \\ ON MEDICINES: CONSTITUTIONAL \\ GUARANTEES OF THE RIGHT TO HEALTH CARE
}

Otávio Augusto Buzar Perroni(*)

\section{RESUMO}

Dentro do novo contexto constitucional-administrativo da regulação setorial, a ANVISA, ostentando os poderes da normatização setorial e de um policiamento contínuo, tem por objetivo regular as atividades concernentes à proteção à saúde. No âmbito de suas atuações, zela pelo escorreito cumprimento dos requisitos para a fabricação, distribuição, comercialização, dispensação e consumo, condizentes com as exigências definidas normativamente para a garantia de boa qualidade do medicamento. $E$, dentre as medidas assecuratórias dessa qualidade, exsurgem o instituto da suspensão cautelar, como um remédio preventivo, decorrente do poder de policia estatal, por meio da qual a autoridade sanitária visa ao atendimento do primário interesse público referente à saúde, e o cancelamento do registro, um instrumento drástico, quando, após transcorrida uma fase processual em que deve ser atendido o princípio do devido processo legal, resta comprovada a nocividade do produto.

\section{Palavras-chave}

Regulação Setorial; ANVISA; Saúde Pública; Vigilância Sanitária; Registro de Medicamentos.

(") Graduando em Direito na Universidade de Brasilia, Pesquisador do Grupo de Estudos em Direito Sanitário - GESAN do Núcleo de Estudos em Regulaçāo Setorial da Universidade de Brasilia. 


\section{ABSTRACT}

In the new constitutional and administrative context of desregulation, ANVISA, holding the powers of field rule and policy, has the purpose of regulate the activities concerning health protection. In its field of acting, ANVISA sees that the fabrication, distribution, commercialization, dispensation and consume requirements are accomplished accordingly to the legal exigencies. And among the affirmative measures of the quality of medicaments there are the institute of preliminary suspension, as a cautious remedy originated of the policy power of the Estate, by which the sanitary authority intends to see that the best public interests concerning health are attended, and the institute of registration cancellation, a drastic instrument used when the harmfulness of the product is demonstrated, after the due process of law.

\section{Key-words}

Sectorial Regulation, ANVISA, Public Health, Sanitary Vigilance, Drug Registration.

\section{INTRODUÇÃO}

Inserida no contexto da reliberalização(1) do Estado, a questão da regulação de setores da atividade social, que em tempos pretéritos se encontravam sob o lume e o punho do "Grande Estado", passou a ser traçada em faces mais complexas dentro do prisma das inter-relações estatal-sociais.

Tratando-se de uma das quebras de paradigma mais relevantes nas quais esteve inserida a sociedade em suas esferas político-econômico e juridica, mormente nesta última, torna-se ululante a necessidade de aclarar ao máximo - ou mesmo solver - os problemas exsurgidos deste novo contexto.

Setores que antes se sujeitavam ao controle monopolista estatal, e. g., o das telecomunicações, o da energia elétrica e o do petróleo, passaram a ser abertos à exploração privada, afigurando-se necessária a criação de entes cujas funções seriam de, aprioristicamente, estabelecer normas às quais estariam sujeitas as empresas particulares, chamadas de concessionárias, a quem o Estado cedeu o direito de explorar tais atividades, e, em momento posterior, verificar se seu desenvolvimento estaria condizente com o definido nas normas editadas pelo ente regulador.

(1) Tendo como caráter central a "re-regulaçăo" de certas atividades antes exploradas exclusivamente pelo Estado. Entretanto, não significando, necessariamente, liberalização normativa. 
Configuram-se, assim, dois os objetivos das chamadas Agências Reguladoras $^{(2)}$ : a produção de normas que exigem o atendimento de certos padrões de comportamento em determinadas atividades sociais e o policiamento da conduta das empresas que se prestaram a tal responsabilidade.

A questão da Vigilância Sanitária insere-se nesse contexto trazendo em seu bojo alguns pontos diferenciadores no tratamento a ela dispensado.

Sendo, no Brasil, o exercício de atividades relacionadas à saúde atribuído há muito tempo aos setores público e privado, optou-se por criar, aproveitando essa "corrente regulatória", uma Agência específica. Então, tentouse acompanhar uma realidade mais dinâmica que o Direito, pelo fato de o tema ensejar discussão de indelével interesse social, qual seja, a proteção da saúde, garantia insculpida na Constituição Federal de 1988 (art. 6º, caput $)^{(3)}$.

Assim, à ANVISA - Agência Nacional de Vigilância Sanitária - foi delegada a competência de, por meio dos poderes de normatização setorial e de um policiamento continuo, regular as atividades concernentes à saúde.

Nisto, então, reside o escopo do presente trabalho: analisar, com o cotejo doutrinário, legal e jurisprudencial, condutas da Agência, nas quais se inserem os institutos da suspensão cautelar e do cancelamento de registro de medicamentos, que visam ao alcance dos objetivos que ela se propôs a atingir.

Desse modo, procurar-se-ão extirpar, ao menos em nivel teórico, os entraves que, eventualmente, venham se afigurando como desafios no caminho de implantação material do direito à saúde.

\section{Conjuntura histórico-econômica}

Tomando em vista a peculiaridade do momento social que ensejou o florescimento das Agências Reguladoras no Brasil - mas não só nele -, houve-se essencial formular um tópico em que se pudessem aclarar os motivos do surgimento de tais entes, o que, por via obliqua, contribuirá, indubitavelmente, para o entendimento escorreito do tema proposto.

(2) Conrado Hübner Mendesadmite que "'agência reguladora' è uma expressão importada do Direito Americano para designar um tipo de ente da Administração Pública ao qual cabe o desempenho de uma tarefa especial: a regulação". MENDES, Conrado Hübner. Reforma do Estado e Agências Reguladoras: estabelecendo os parâmetros de discussāo. In: SUNDFELD, Carlos Ari [coord.]. Direito Administrativo Econômico. São Paulo: Malheiros, 2000. pp. 107 e 108.

(3) "São direitos sociais a educação, a saúde, o trabalho (...) na forma desta Constituição" (grifo nosso). 
Tendo percorrido uma época influenciada pelas teorias liberalistas econômicas, as sociedades contemporâneas adentraram o século XX já na iminência de profunda modificação em suas estruturas estatais.

O abstencionismo econômico, fruto da teoria liberal clássica de Adam Smith, foi sendo suplantado com o surgimento das ditas "Constituições Sociais", dentre as quais as pioneiras Constituição do México, em 1917, e de Weimar, dois anos depois, em face da contraposição desses Estados às idéias estritamente formais de liberdade e igualdade brotadas da Revolução Francesa.

Procurou-se, então, nesses novos Estados, concretizar a realização desse ideal por meio de uma "positivação social", encalçada nas Cartas Constitucionais, devendo ser garantida pela força do próprio Estado. Desse modo, o intervencionismo estatal vai-se caracterizando como único meio eficaz para o exercício pleno dos direitos sociais.

Tal quadro acentuou-se com a crise de 1929 e o New Deal de Roosevelt, demandando a sociedade que o Estado, por meio de sua máquina burocrática e sua estrutura físico-financeira, passasse a controlar um incomensurável número de atividades, inclusive a econômica.

Assim, foi adquirindo, com poder sobre diversos ramos sociais, um aspecto de super-Estado, com atividades cada vez mais abrangentes e encargos proporcionalmente mais onerosos.

$O$ intervencionismo(4) teve seu auge no periodo da $2^{\text {Guerra Mundial, }}$ com o surgimento dos regimes totalitários - os nazi-fascistas europeus e o comunista soviético, mas especificamente - e só começou a dar sinais de fraqueza na década de 70, na qual, além das crises do petróleo, afiguraram-se "a ineficiência da máquina estatal, salvo raras exceções, o agigantamento do Estado e, entre outros fatores, a incapacidade de gerir com eficiência um sem-número de empresas estatais"(5), passando a ser a tendência global a "reprivatização e a reliberalização da economia"(6).

Nesse enfoque, o Estado passou a delegar determinadas atividades, antes exclusivamente por ele exercidas, a terceiros, ressaltando-se, então, a necessidade de serem criados instrumentos de regulação mantenedores da idoneidade e da eficiência dos serviços prestados, identificados sob três formas: "regulação estatal, regulação do mercado (nos moldes da 'māo-invisível' de Smith) e a auto-regulaçăo"(r).

(4) Entenda-se "intervencionismo" em sentido amplo, na medida em que se possibilita ao Estado intervir em atividades estatais ou privadas, năo devendo ser confundido, pois, com a intervençāo estatal estritamente técnico-juridica.

(5) MENDES, op. cit., p. 110.

(6) Ibidem.

(7) Ibidem, D. 111. 
"Enquanto a regulação natural do mercado obedece à lógica do interesse pessoal de cada agente e rege-se pelo princípio da concorrência, ou seja, de liberdade de competição, a regulação estatal obedece ao interesse público, tendo como princípio ordenador a regulação autoritária, através [sic] da imposição de normas, do poder estatal. Entremeando estas duas, a auto-regulação por entidades associativas mescla uma lógica do interesse público e do interesse privado, norteando-se pelo princípio da autodisciplina, uma vez que os próprios sujeitos regulados se encarregam pela normatização de suas condutas. ${ }^{n(8)}$ (grifos no original)

Infere-se, então, que o escopo das Agências Reguladoras, entre as quais a ANVISA, é, se não outro, o de regular uma atividade específica de relevância social e de primar por sua idônea manutenção, com o fim de atender, sobretudo, ao interesse público, dentro do sistema optado pelo ordenamento pátrio.

\section{Da natureza da ANVISA}

No ensejo do comprometimento da Constituição Federal de 1988 com os direitos sociais, definiu-se "saúde" como sendo "direito de todos e dever do Estado, garantido mediante políticas sociais e econômicas que visem à redução do risco de doença e outros agravos e ao acesso universal e igualitário às ações e serviços para sua promoção, proteção e recuperação" (art. 196).

Desse modo, foi atribuída ao Estado a tutela de tal bem jurídico, pois, sendo de relevância pública as ações e serviços de saúde, só ao Poder Público cabe "dispor, nos termos da lei, sobre sua regulamentação, fiscalização e controle, devendo sua execução ser feita diretamente ou através de terceiros e, também, por pessoa física ou jurídica de direito privado" (art. 197).

Com a exploração desse campo, também no orbe de competências do Estado incidiu a tarefa de "fiscalizar" a atividade de "terceiros", agentes no sistema social da saúde, dentre os quais prestadores de serviços médicos, produtores de equipamentos para saúde, fabricantes de medicamentos, de alimentos, de saneantes domissanitários e outros.

Carlos Ari Sundfeld afirma que

"a existência de agências reguladoras resulta da necessidade de o Estado influir na organização das relações econômicas de modo muito constante e profundo, com o emprego de instrumentos de autoridade,

(8) MOREIRA, Vital, apudMENDES, ibidem, pp. 111 e 112. 
e do desejo de conferir, às autoridades incumbidas dessa intervenção, boa dose de autonomia frente à estrutura tradicional de poder político."(9) (grifado no original)

Não obstante a eloqüência inquestionável de que se reveste tal excerto, foi olvidada a inclusão da intervenção estatal também no âmbito das relações sociais, dado que a própria Constituição sublimou a patamares de elevada altitude os chamados "direitos sociais", entre os quais a educação e a saúde (CF/88, art. $6^{\circ}$, caput).

Assim, também na esfera da proteção à saúde, definiu-se necessária a criação de uma agência reguladora.

Reza, entretanto, a Carta Magna de 88 , em seu art. 37 , inciso XIX, que "somente por lei específica poderá ser criada autarquia e autorizada a instituição de empresa pública, de sociedade de economia mista e de fundação, cabendo à lei complementar, neste último caso, definir áreas de sua atuação".

Desse modo, no ano de 1999, atendendo ao preceito constitucional, foi promulgada a Lei $n$. 9.782, definindo o Sistema Nacional de Vigilância Sanitária e criando a Agência Nacional de Vigilância Sanitária - ANVS, posteriormente renomeada ANVISA.

À Agência atribuiu-se a natureza de autarquia especial, caracterizada pela independência administrativa, estabilidade de seus dirigentes e autonomia financeira ${ }^{(10)}$, sendo sua finalidade institucional precípua

"promover a proteção da saúde da população, por intermédio do controle sanitário da produção e da comercialização de produtos e serviços submetidos à vigilância sanitária, inclusive dos ambientes, processos, dos insumos e das tecnologias a eles relacionados, bem como o controle de portos, aeroportos e de fronteiras" (Lei n. 9.782/99, art. 6\%).

Dentre outras competências da Agência, no art. $7^{\circ}$ do referido diploma legal reside uma que remete diretamente à sua função normatizadora:

"Art. $7^{\circ}$ Omissis

(9) SUNDFELD, Carlos Ari. Introdução às Agências Reguladoras. In: SUNDFELD, Carlos Ari (coord.). Direito Administrativo Econômico. São Paulo: Malheiros, 2000. p. 18.

(10) Sundfeld identifica algumas características comuns das agências, mesmo não tendo elas seguido um modelo comum. Os pontos convergentes consistem em: serem entidades com tarefa tipicamente de Estado; gozarem de autonomia em relação ao Executivo; e ordenarem setores básicos da economia. SUNDFELD, ibidem. p. 19. 
III - estabelecer normas, propor, acompanhar e executar as politicas, as diretrizes e as ações de vigilância sanitária;

...".

Aqui, poder-se-ia questionar a usurpação, por parte do Executivo, do poder de legislar, mas, de forma acurada, Sundfeld explica a necessidade de às Agências reguladoras ser conferido certo poder normativo, em face da ineficiência e incapacidade da Lei, em sentido estrito, para definir padrões de comportamento em atividades muito específicas, sendo, de certa forma, até mesmo inexigivel sua regulamentação por meio do Poder Legislativo.

Indigitado administrativista afirma que,

"para realizar os interesses gerais da atualidade no contexto de um Estado intervencionista, não basta editar uma lei abstrata, genérica e distante, dizendo, por exemplo, que nenhuma exploração da atividade industrial pode ultrapassar certo limite de poluição, causando dano à saúde do vizinho. É preciso que o Estado vá trabalhando com a realidade todo o tempo, para definir, nas situações que se põem, o que é ou não uma emissão de poluentes aceitável (...)"(11).

Afigura-se, destarte, legítima a atribuição normatizadora da Agência Nacional de Vigilância Sanitária. Essa afirmação tem importância inquestionável, já que grande parte dos processos judiciais que envolvem a ANVISA ou a antiga Secretaria Nacional de Vigilância Sanitária, por aquela subsumida, remetem à indagação da legalidade de tais documentos normativos, quase sempre com pretensão à uma descaracterização de sua incidência e imperatividade, nos casos concretos em que se guerreiam os atos da autoridade competente da Vigilância Sanitária respaldados nessas normas.

\section{Das atividades da Agência Nacional de Vigilância Sanitária}

Hélio Pereira Dias (12) afirma que "nenhum bem da vida apresenta tão claramente unidos o interesse individual ao interesse social como o da saúde. E, para protegê-lo, baldados os esforços suasórios e de educação, dispõe a Administração de Poder de Polícia".

Por poder de polícia entende-se a atribuição "de que dispōe a Administração Pública para condicionar o uso, o gozo e a disposição da propriedade

(11) SUNDFELD, op. cit., p. 28.

(12) DIAS, Hélio Pereira. Teoria e prática do processo administrativo sanitário. Brasilia: [s.n.], 1988. p. 9. 
e o exercício da liberdade dos administrados no interesse público ou social"(13).

Assim, dentro do rol das competências da ANVISA definidas na Lei $n$. 9.782/99, insere-se a de normatizar, controlar, fiscalizar produtos, substâncias e serviços de interesse para a saúde (art. $2^{9}$, III), por meio do estabelecimento de normas, propondo, acompanhando e executando as políticas, dirctrizes e ações de vigilância sanitária (art. $7^{\circ}, 111$ ).

Ainda no texto do art. $7^{\circ}$, inciso IX, ficou incumbida a Agência de conceder registros de produtos, seguindo as normas de sua área de atuação, definindo o artigo seguinte o que vêm a ser, especificamente, esses produtos sob sua vigilância:

"Art. 8 Omissis

$\S 1^{2}$ - Consideram-se bens e produtos submetidos ao controle e fiscalização sanitária pela Agência:

1 - medicamentos de uso humano, suas substâncias ativas e demais insumos, processos e tecnologias; ...".

Tratando-se de medicamento, extrai-se uma definição insculpida na Lei n. 5.991, de 1973, sendo considerado como tal, no art. 4. II, todo "produto farmacêutico, tecnicamente obtido ou elaborado, com finalidade profilática, curativa, paliativa ou para fins de diagnóstico", diferenciando-se, assim, dos conceitos de droga e de insumo farmacêutico, delineados, respectivamente, nos incisos I e III do mesmo artigo.

Respeitando a legislação anterior, à Agência foi delegada a regulamentação, o controle e a fiscalização de medicamentos.

Ressalte-se, entretanto, que o termo "legislação" deve ser compreendido cum grano salis. Hélio Pereira Dias(14) destaca que "não só as normas previstas em leis e em seus decretos constituem o repertório cuja transgressão é sancionável. Também as normas técnicas consubstanciadas em outros atos emanados dos órgāos competentes de vigilância sanitária constituem obrigações a serem observadas pelos particulares", sujeição essa que tem ensejado a discussão via judicial a respeito de Resoluções e Portarias editadas pela Secretaria de Vigilância Sanitária, órgāo antecessor da ANVI$\mathrm{SA}$, em casos concretos (vide n. 5 , infra).

(13) GASPARINI, Diogenes. Direito Administrativo. $5^{\bullet}$ ed. rev. atual. e amp. São Paulo: Saraiva, 2000. p. 115.

(14) DIAS. Teoria e prática..., cit., D. 19. 
A Lei n. 6.360/76, regulamentada pelo Decreto n. 79.094/77, instituiu, então, o regime da vigilância sanitária a que se sujeitam os medicamentos e todos os demais produtos e serviços ligados às atividades de saúde, devendo, inclusive, os atos da autoridade sanitária atender aos preceitos por ela impostos.

Ficaram definidos, ainda no mesmo documento legal, como atribuição exclusiva do Ministério da Saúde, o registro e a permissão de uso de medicamentos, bem como a aprovação ou exigência de modificação de seus componentes (art. $6^{9}$, parágrafo único). $E$, em seu art. $7^{\circ}$, estabeleceu que, "como medida de segurança sanitária e à vista de razões fundamentadas do órgão competente, poderá o Ministério da Saúde, a qualquer momento, suspender a fabricação e venda de qualquer dos produtos de que trata esta Lei, que, embora registrado, se torne suspeito de ter efeitos nocivos à saúde humana".

No intuito de aclarar conjunturas nebulosas que viessem a surgir posteriormente, o legislador, a par dessa discussão, houve por bem tecer o conceito do que vem a ser "registro", no art. $4^{2}$, inciso X, daquela Lei de 1976:

" $X$ - Registro - Inscrição, em livro próprio após o despacho concessivo do dirigente do órgão do Ministério da Saúde, sob número de ordem, dos produtos de que trata esta Lei, com a indicação do nome, fabricante, da procedência, finalidade e dos outros elementos que os caracterizem".

Ademais, definiu requisitos específicos no tangente ao registro de drogas, medicamentos e insumos farmacêuticos ${ }^{(15)}$, prevendo a possibilidade de, no caso de não serem atendidos, cancelar-se o registro sempre que "efetuada modificação não autorizada em sua fórmula, dosagem, condições de fabricação, indicação de aplicações e especificações enunciadas em bulas, rótulos ou publicidade ${ }^{m(16)}$.

Dispõem os arts. 62 a 67 sobre infrações e penalidades, definindo em que ocasiões se considera o medicamento como alterado, adulterado ou impróprio para uso.

Refletindo o caráter policiador da Agência, a apuração das infrações "far-se-á mediante apreensão de amostras e interdição do produto ou do estabelecimento, conforme disposto em regulamento" (art. 72), e a comprovação da ocorrência da infração dá ensejo à atividade da autoridade competente, em conformidade com cada situação, sendo-lhe atribuido o poder de apreender ou inutilizar o produto, em todo o território nacional, cancelar o registro ou cassar a licença do estabelecimento (art. $72, \S 1^{\circ}$ ).

(15) Ver art. 16 da Lei n. 6.360/76.

(16) Art. 19 da Lei n. 6.360/76. 
A apuração deve atender aos princípios do devido processo legal, possibilitando aos sujeitos dos pólos ativo e passivo da relação juridica material a defesa de seus interesses na relação processual.

A ulterior Lei n. 6.437, de 1977, esmiúça as modalidades de infrações e penalidades cabíveis no processo administrativo sanitário.

No caput de seu art. $2^{\circ}$, define que,

"sem prejuizo das sanções de natureza civil ou penal, as infrações sanitárias serão punidas, alternativa ou cumulativamente, com as penalidades de:

VI - suspensão de vendas e/ou fabricação de produto;

VII - cancelamento de registro de produto;

...".

Classificando as infrações sanitárias em leves, graves e gravíssimas, definiu, ainda, circunstâncias atenuantes e agravantes a serem relevadas durante a verificação procedimental e aplicação das penalidades.

\section{Da suspensão cautelar e do cancelamento de registro de medicamentos}

Acerca da definição do que vem a ser "registro", do conceito genérico fornecido pela Lei n. 6.360/76, podem ser identificados apenas o órgão concessor, o Ministério da Saúde, e as informaçōes que devem estar contidas no documento.

Já o art. 3², XVII, do Decreto n. 79.094/77 tece uma definição teleológica, pois explicita ser "destinado a comprovar o direito de fabricação de produto submetido ao regime da Lei n. 6.360/76".

Em outras palavras, a finalidade principal do registro do produto é garantir que sejam entregues à população medicamentos que contenham componentes eficazes e que atendam à destinação terapêutica indicada(17).

É mister, no entanto, diferenciar o instituto do registro dos de licença e de autorização. O primeiro refere-se a produto, englobando medicamentos, drogas, insumos farmacêuticos e outros, ao passo que os demais, respectivamente, tocam à idéia de estabelecimento e de funcionamento de empresa.

(17) GOMES, Carolina et alii. Vigilância Sanitária de Medicamentos e Correlatos. $1^{\text {a }}$ ed. Rio de Janeiro: Quality Mark, [200-?], p. 65. 
Diferencia-se, ainda, do conceito de patente; segundo Ela Wiecko Volkmer de Castilho(18), inclui-se este

"no conceito de propriedade industrial, que, por sua vez, faz parte do conceito mais amplo de propriedade intelectual. (...) A patente de invenção materializa-se em um documento, emitido por um órgão estatal, que descreve uma invenção (inovação) e cria uma situação juridica, em que a invenção somente pode ser explorada comercialmente (produzida, utilizada, vendida, importada), por um tempo determinado, pelo concessionário da patente ou com a autorização deste".

Assim, a patente não dá direito à comercialização ab initio do produto, adquirido somente sob o lume da concessão do registro, pois apenas a partir desse momento garante-se sua qualidade e eficácia pelo fato de ter sido analisado nas várias fases da vigilância.

No que tange a seu periodo de validade, terá o registro vigência de cinco anos e deverá ser concedido no prazo máximo de 90 dias (Lei n. 6.360/ 76 , art. 12), podendo ser revalidado por periodos iguais e sucessivos.

Não obstante essa norma, o ato de registro não se exaure em um momento pontual, ou seja, o medicamento que tenha sido submetido ao processo de registro não conta com aval sanitário incondicionado ad eternum. Ao contrário, está sempre sujeito à análise de circunstâncias, como, v.g., mudança nas instalações da fabricante, reforma nas estruturas físicas, utilização de maquinário novo.

Assim, o registro pressupõe certos requisitos no momento de sua concessão, mas, ocorrendo mudança que venha a eivar de vícios alguma das características exigidas, mesmo ainda dentro de seu periodo de validade, dá-se causa à ação da Vigilância Sanitária, que, analisando as conseqüências, pode configurar, inclusive, a cassação do registro de certo medicamento.

Com efeito, considera-se o registro como condição resolutiva para o pleno exercício do direito de propriedade privada, ou seja, estar-se-ia, com a exigência de registro, simplesmente exercendo a atividade administrativa garantidora dos verdadeiros contornos de propriedade ligados a requisitos de saúde pública, sem, entretanto, sacrificar o direito do particular em comercializar certo medicamento.

Nesse ponto reside a questão da contraposição entre o interesse individual - o de gerar renda a um particular por meio da venda de medicamen-

(18) CASTILHO, Ela Wiecko Volkmer de. Patentes de produtos de origem biológica. In: ARANHA, Márcio Iório; PICARELLI, Márcia Flávia Santini (org.). Política de patentes em saúde humana. São Paulo: Atlas, 2001, p. 70. 
to - e o interesse coletivo - o de obter acesso a um sistema de saúde confiável e de qualidade - muito discutida na esfera jurisprudencial (vide $\mathrm{n}$. 5, infra).

Tendo em vista que, na área da Saúde, risco é sinônimo de probabilidade, a relação entre os órgãos da Vigilância Sanitária e os seus regulados deve ser feita no intuito de proteger o direito à saúde, constitucionalmente garantido, em três niveis: o da prevenção, momento em que são concedidos registros e autorizações embasados nos documentos legais (leis, normas técnicas, portarias, regulamentos, etc.); o da vigilância, por meio das revalidações de registros, análises e inspeções; e o da correção, aplicando-se punições às infrações.

Assim, para garantir a qualidade de um medicamento ao ponto de torná-lo disponivel à população, o procedimento de concessão de registro deve submeter o produto a uma análise minuciosa em suas diversas fases, desde a produção até a comercialização.

Em primeiro lugar, todo medicamento inovador deve superar o crivo de uma pesquisa clínica, em que serão aplicados os conhecimentos científicos e insumos tecnológicos no desenvolvimento de um produto que se propõe a ter eficácia em determinada atividade.

A Vigilância Sanitária deve, antes de cogitar a concessão do registro, verificar se durante as pesquisas de laboratório, com animais e com seres humanos de forma controlada (subfases da pesquisa clínica), os efeitos a que o medicamento se propôs a proporcionar no organismo foram eficazes e seguros.

Após a confirmação da qualidade do produto e, em vias de conseqüência, da concessão do registro, o papel da Vigilância, ainda no âmbito preventivo, denominado farmacovigilância, passa a ser o de verificar se as estruturas da produção (instalações, maquinário, risco de contaminação, área de ventilação, etc.), de distribuição (embalagem, rotulagem, transporte), comercialização, dispensação e consumo condizem com as exigências definidas normativamente para a garantia de boa qualidade do medicamento (sendo essa verificação também exeqüível em relação a produtos já tradicionais, $i$. e., não inovadores).

Verificando a ANVISA algum desvio ao padrão imposto pelas normas, fica imbuída, então, de poder punitivo/corretivo, em decorrência da infração cometida pelo estabelecimento.

Como antes referido, a Lei n. 6.437/77, em seu art. $2^{\circ}$, definiu como sanções administrativas sanitárias, dentre outras, a suspensão de vendas e/ ou fabricação de produto e o cancelamento de registro de produto. 
A imposição dessas duas medidas punitivas tem ensejado frugífera discussão jurisprudencial, visto que a natureza e as implicações jurídicas das duas divergem em alguns pontos.

As infrações sanitárias submetidas à punição mediante a suspensão cautelar e/ou cancelamento do registro estão arroladas, junto com as demais, no art. 10 da Lei n. 6.437/77 $7^{(19)}$.

A apuração do ilicito deve ser realizada mediante a apreensão de amostras para realização de análise fiscal e de interdição, se for o caso (Lei $n$. $6.437 / 77$, art. 23). E é nesse ponto que começam a se tornar visiveis as diferenças entre a suspensão cautelar da venda de medicamentos e o cancelamento de seu registro.

Malgrado o legislador tenha se esquivado de tecer um conceito definidor de tais institutos, é possível traçar-lhes um liame diferenciador, mesmo que, às vezes, possa parecer de etérea e sinuosa natureza tal separação, por meio de uma interpretação sistemática do conjunto das normas sanitárias (legais e regulamentares), mormente a Lei $n .6 .437 / 77$ e o Decreto $n$. $79.094 / 77$, no tangente às infrações sanitárias e respectivas punições.

A Lei define que a apreensão de amostras para efeito de análise, fiscal ou de controle, não será acompanhada de interdição do produto, excetuando-se os casos em que sejam flagrantes os indícios de alteração ou adulteração do produto, hipótese em que a interdição terá caráter preventivo ou cautelar.

Entretanto, a interdição de medicamento "será obrigatória quando resultarem provadas, em análises de laboratório ou no exame de processos, ações fraudulentas que impliquem falsificação ou adulteração" (art. 23, $\S 3^{2}$, sem grifo), cabendo, desse modo, o cancelamento do registro, nas infrações que o prevejam como sanção.

Das linhas acima, deduz-se que à suspensão cautelar foi dado caráter de excepcionalidade, devendo a interdição do medicamento, como rege o $\S 4^{2}$ do art. 23 daquela Lei, durar "o tempo necessário à realização de testes, provas, análises ou outras providèncias requeridas, não podendo, em qualquer caso, exceder o prazo de 90 (noventa) dias, findo o qual o produto ou estabelecimento será automaticamente liberado".

Infere-se, ainda, do caput do art. $6^{2}$ da Lei n. $6.360 / 76$ que a suspensão cautelar é o passo anterior ao cancelamento do registro: "a comprova-

(19) A Medida Provisória n. 2.190-34, de 23 de agosto de 2001 (reediçăo da originária n. 1.814, de 16 de fevereiro de 1999), adicionou os incisos XXXII a XLI, prevendo novas modalidades de infraçóes sanitárias sujeitas à punição mediante suspensảo cautelar ou cancelamento do registro. 
ção de que determinado produto, até então considerado útil, é nocivo à saúde ou não preenche os requisitos estabelecidos em lei, implica a sua retirada imediata do comércio e a exigência da modificação da fórmula de sua composição e dos dizeres dos rótulos, das bulas, das embalagens, sob pena de cancelamento do produto em todo o território nacional" (sem grifo no original).

A "comprovação" a que se refere tal artigo remete à previsão do art. 23 , $\S 2^{\circ}$, da Lei n. 6.437 , definida como "indícios de adulteração ou alteração flagrantes", requisitos anteriores ao cancelamento e que ensejam a suspensão cautelar da venda ou fabricação de medicamentos, embasados em pareceres técnicos de órgãos supervisores atrelados à Vigilância Sanitária.

Não há de questionar-se a violação do due process of law por dois motivos. Em primeiro lugar, porque ao Poder Público, nas figuras de seu Ministério da Saúde e da ANVISA, foi delegado legalmente o poder de delinear sua atividade dessa maneira, primando pelo atendimento ao princípio constitucional que define ser a saúde um direito a ser resguardado pelo Estado (CF, art. 196). Depois, pelo fato de o interesse público primário de preservação da saúde exercer caráter de supremacia sobre os interesses do particular.

A imediata retirada do medicamento do mercado não implica, destarte, uma desvirtuação do devido processo legal, já que, ao administrado, as vias contenciosa administrativa e mesmo a judicial comum estão sempre abertas. Entretanto, ao Administrador é exigivel que, nos casos em que a segurança do medicamento, eficácia para o fim a que se propõe, identidade, atividade, qualidade, prazo e inocuidade necessárias (ut art. 16, II, Lei n. 6.360/76) residam em flagrante descumprimento às normas estabelecidas, resguarde a sociedade de potenciais efeitos nocivos à saúde, por meio da suspensão cautelar de vendas de determinado medicamento, até que se prove a sua idoneidade ao uso.

Desse modo, afigurou-se necessário ao Poder Público proteger aquele interesse primário de uma sociedade que se encontrava ao léu de interesses de comerciantes e produtores de medicamentos.

Mediante tal cautela, ao fim do prazo legal de 90 dias, não sendo comprovada a nocividade levada à suspeição pela via técnica ou processual, retornarão ao mercado os medicamentos suspensos, por meio de despacho da autoridade competente, liberando-o e considerando-o próprio para uso.

Diversa há de ser a conduta do Poder Público se, entretanto, como resultado de laudo laboratorial, for confirmada a suspeita de que alguma das 
características do produto está em desacordo com as normas de qualidade e segurança impostas pela autoridade competente. Nesse caso, a autoridade sanitária lavrará o termo de punição, fazendo constar no processo o despacho técnico respectivo que tenha reprovado o medicamento, podendo optar, dentre outras punições cabíveis, pela aplicação da pena de cancelamento do registro do produto.

\section{Dispõe o Decreto n. 79.094/77:}

"Art. $7^{\circ}$ Quando verificado que determinado produto, até então considerado útil, é nocivo à saúde ou não preenche os requisitos estabelecidos, o órgão de vigilância sanitária competente do Ministério da Saúde exigirá a modificação devida na fórmula de composição e nos dizeres dos rótulos, das bulas e embalagens, sob pena de cancelamento do registro e da apreensão do produto em todo o território nacional.

Art 8 Como medida de segurança sanitária e à vista de razões fundamentadas, o órgão de vigilância sanitária competente do Ministério da Saúde poderá, a qualquer momento, suspender a fabricação e venda de qualquer dos produtos de que trata este Regulamento, o qual, embora registrado, se torne suspeito de ter efeitos nocivos à saúde humana.

Parágrafo único. O cancelamento do registro previsto neste artigo, pelo órgão de vigilância sanitária competente do Ministério da Saúde, dependerá do pronunciamento da câmara técnica competente do ConseIho Nacional de Saúde, sendo facultado à empresa o direito de produzir provas de caráter técnico-científico para demonstrar a improcedência da suspeição levantada."

Ressalte-se que a previsão legal que faculta ao administrado "o direito de produzir prova" remete apenas à hipótese de cancelamento de registro.

Poder-se-ia questionar a constitucionalidade de tal excerto, tendo em vista que 0 art. 5, IV, da CF/88 apregoa serem "assegurados aos litigantes, em processo judicial ou administrativo, e aos acusados em geral (...) o contraditório e a ampla defesa, com os meios e recursos a ela inerentes".

Porém, sob os auspícios do Ministério Público(20), trazem-se à baila os motivos pelos quais resolveu o legislador definir, da maneira como foi feita, o tratamento dispensado pelo Poder Público à proteção da saúde:

"Como observado, existe um outro bem juridicamente protegido por várias normas constitucionais: trata-se do conceito de 'saúde pública' 
ao qual se dedicou toda uma seção do título da Constituição denominada 'ordem social'. Sobre o tema, a Constituição da República estatui que 'a saúde é direito de todos e dever do Estado, garantido mediante políticas sociais e econômicas que visem à redução do risco de doenças e de outros agravos e ao acesso universal e igualitário às ações e serviços para sua promoção, proteção' (art. 196).

Donde tem-se configurado o conflito de bens protegidos na Constituição: de um lado, a ampla defesa; de outro, a saúde pública".

O parquet clama, de modo louvável, por princípios de interpretação elencados na doutrina de Hesse, na qual

"o princípio da concordância prática está em estreita conexão com isso [em referência à unidade da Constituição]: na resolução dos problemas, os bens constitucionalmente protegidos devem ser reciprocamente ordenados, de modo que a cada um deles ganhe realidade. Onde surgem colisões, não é permitido realizar um deles às custas do outro, por meio de uma precipitada 'ponderação de bens' ou mesmo pela abstrata 'ponderação de valores'. Antes, o princípio da unidade da Constituição impõe a tarefa de uma 'otimização': os limites de ambos os bens devem ser retraídos, para que ambos possam atingir uma ótima eficácia" (grifado no original).

Desse modo, o legislador ordinário, de maneira plausível, conseguiu atender a ambos os interesses: ao público, na medida em que garante a proteção da saúde, e ao privado, quando garante o contraditório e a ampla defesa na via processual.

Ao elevar a saúde pública a esse pedestal, a Lei atribuiu à autoridade saritária o poder de, por meio da suspensão cautelar, prevenir a coletividade, em seu direito à saúde, de se tornar contaminada por vícios potencialmente lesivos à vida humana.

No mesmo passo, calcou no texto legal a previsão de o particular, fabricante ou fornecedor de medicamentos, no iter de um devido processo legal, defender seu interesse justo e também garantido constitucionalmente de realizar atividade com fins lucrativos e alegar processualmente, por meio de estudos, pesquisas científicas e pareceres técnicos, a idoneidade de seu produto, antes que venha a ter seu registro cassado pela autoridade sanitária competente.

Visando a atender o valor maior da vida humana, previu uma medida célere - logo, mais eficaz -, "para interditar ou suspender temporariamente a produção e a entrega ao consumo de medicamentos que ponham em risco a saúde humana"(21). Esquivou-se, assim, de correr o risco de, ao exigir

(21) Idem. 
um procedimento com demasiados entraves burocráticos em um processo muito intrincado de suspensão cautelar, não atingir a proteção à saúde pública demandada constitucionalmente.

Portanto, diversamente do tratamento exigido para a interdição cautelar - rectius: suspensão de venda de medicamentos - o cancelamento de registro admite, por ser uma medida mais drástica, dilação probatória no atendimento aos princípios da ampla defesa e de garantia do contraditório.

Dispõe o art. 22 do Decreto n. 79.094/77 que "o registro de drogas, medicamentos e insumos farmacêuticos será cancelado sempre que efetuada qualquer modificação em sua fórmula, dosagem, condições de fabricação e indicação de aplicações e especificações enunciadas em bulas, rótulos ou publicidade não autorizada pelo Ministério da Saúde".

Desse art. 22, in fine, infere-se que somente se não satisfeitas as exigências do órgão competente, no caso a ANVISA, vinculada ao Ministério da Saúde, dar-se-á ensejo ao processo de cancelamento do registro do medicamento.

Exige a autoridade que haja "justificativa da mudança pretendida, comprovação científica pertinente, literatura pertinente", dentre outros ${ }^{(22)}$. E só é possivel levantarem-se tais informaçōes no decorrer de um processo alongado, munido de dilação probatória, residindo aqui a razão de, no caso do cancelamento de registro, diversamente do que ocorre na suspensão cautelar, em que o risco e os vícios do medicamento são causticantes, exigir a comprovação dos motivos de modificação das características do produto ou de suas fases de produção e comercialização.

\section{Entendimento jurisprudencial - interpretação do direito à saúde}

Nos dizeres de Hélio Pereira Dias ${ }^{(23)}$,

"na interpretação do Direito de Saúde, a exemplo do que ocorre no direito Administrativo, além da utilização analógica das regras de hermenêutica em geral, devem ser considerados três fatores fundamentais: $\left.1^{\text {}}\right)$ a desigualdade jurídica entre a Administração e os administrados (dada a prevalência dos interesse coletivos sobre os individuais); $2^{\circ}$ ) a presunção de legitimidade dos atos da Administração (premissa de conduta legal nos atos administrativos, que transfere para o particular o ônus de provar o contrário, isto é, demonstrar que a Administração não atuou nos limites da lei, agindo, portanto, arbitrariamente); $\left.3^{2}\right)$ a necessidade de poderes discricionários para a Administração rea-

(22) Art. 23.

(23) Em palestra proferida no dia 13 de julho de 2001, na Superintendência de Vigilância Sanitária da Secretaria de Saúde do estado de Minas Gerais. 
lizar seus fins, entendidos aqueles primeiros como a soma de competências facultadas pela lei ao administrador, para escolher a oportunidade, a conveniência e o conteúdo dos atos".

Adiciona, ainda, que, sendo a saúde pública um direito social (art. $6^{2}$, CF/88), o instrumento materializador de tal garantia social reside no "exercicio fiscalizador sanitário da produção de medicamentos".

Desse modo, guardando o direito à saúde traços característicos dos direitos difusos, mormente os que remetem ao Direito do Consumidor, é demandada uma tutela do Estado no que diz respeito à proteção da saúde do consumidor.

Assim, ao Ministério Público foi entregue a insígnia de legítimo curador do direito à saúde, com respaldo na Carta Magna de 88, art. 129, III.

E plausivel tem-se afigurado tal zelo constitucional, peio fato de os pareceres exarados pelos órgãos do parquet virem sendo elencados como razões com as quais aquiescem os magistrados na fundamentação de suas sentenças em processos cujo objeto se refere à vigilância sanitária.

Nesse ânimo, traz-se à baila a análise do Mandado de Segurança $n$. 94.12039-7, no intuito de exemplificar casuisticamente o tema abordado nas linhas anteriores ${ }^{(24)}$.

Na sentença do juízo a quo do caso em tela (16 Vara Federal da Seção Judiciária de Brasília - DF), a segurança foi concedida com lastro no parecer do Ministério Público que iluminou o ato da autoridade impetrada sob dois focos: o primeiro, concernente ao poder-dever atribuído aos órgãos da Vigilância Sanitária, com respaldo legal (Lei n. 6.360/76, arts. $7^{\circ}$ e $8^{\circ}$ ), de suspender cautelarmente a venda de um medicamento que, mesmo até certo momento considerado útil, passou a ensejar dúvidas no tangente à sua qualidade; o segundo, referente à garantia que se dá ao fabricante do produto suspenso para comprovar sua eficácia, no período legalmente definido, sot pena de, não o fazendo, ter o registro cancelado.

Vê-se que a suspensão da venda em face de uma suspeição por parte da vigilância sanitária, no que diz respeito à qualidade do produto, é anterior ao cancelamento do registro.

Procedendo de tal maneira, a Vigilância Sanitária está protegendo o interesse primário da sociedade de ter garantido seu direito à saúde, defendendo-a de potenciais riscos.

(24) Sobre o tema, conferir os Mandados de Segurança n. 95.00533-6, n. 95.03981-8 e n. 97.246165 , sendo os dois primeiros originários da $16^{*}$ Vara Federal de Brasilia - DF e o terceiro, da $3^{*}$ Vara dessa mesma Seção Judiciária. 
No entanto, in casu, a autoridade impetrada não notificou a empresa impetrante exigindo a comprovação, com espeque laboratorial da qualidade de seu medicamento, cujo registro foi cancelado.

Atuando de tal maneira, o direito à ampla defesa e ao contraditório da autora foi violado, residindo aí a causa de pedir.

Demandou a autora que a autoridade sanitária observasse os procedimentos legais atinentes ao cancelamento de registro para que, antes de o consumar, procedesse ao reexame das condições do registro, outrora por ela concedido, analisando, para isso, as razões tecnicamente fundamentadas a serem levantadas pela impetrante no curso de um processo administrativo e, somente se persistir a suspeição a respeito da idoneidade do medicamento depois de transcorrida essa fase processual, que instaurasse o processo devido de cancelamento de seu registro, em atendimento ao interesse da coletividade.

Dessa forma, a decisão do Juiz de 1 Instância vem cortejada pela razão, pelo fato de exigir que a autoridade coatora se manifestasse no sentido de suspender o ato de cancelamento do registro, mantendo o produto, porém, em regime de suspensão cautelar até que as razões da empresa impetrante, acostadas em provas de caráter técnico-científico, fossem analisadas. Em seguida, deveria proceder da maneira exigida pela lei: em caso de confirmação da suspeição levantada, tendo sido inócuos os motivos da impetrante, cancelando o registro; em caso contrário, o de comprovação da idoneidade do medicamento, ou no caso de inércia da autoridade coatora no período legal de 90 dias, fazendo com que o produto retornasse ao mercado, sendo considerado, a partir dai, adequado para uso.

\section{CONCLUSÕES}

Com todo o exposto, restou claro que à ANVISA, como sucessora da SVS, dentro de suas competências auferidas dos textos legais, delegou-se o poder-dever de primar por um direito à saúde, constitucionalmente consagrado, com o uso de medidas de prevenção, de acompanhamento e de punição.

Entretanto, algumas dessas ferramentas não foram claramente diferenciadas, chegando, em certos pontos, a se imiscuir, como no caso da suspensão cautelar e do cancelamento do registro de medicamento.

Necessária tornou-se, então, a elucidação de tais conceitos, tanto no âmbito abstrato, com a exposição de excertos doutrinários e do próprio texto legal, quanto no orbe concreto, em que se analisaram as conseqüências materiais de tal discussão entre suas definições nas páginas dos jurisprudentes. 
Então, definiu-se o instituto da suspensão cautelar de medicamentos como medida preventiva, decorrente do poder de polícia estatal, por meio da qual a autoridade sanitária visa ao atendimento do primário interesse público referente à saúde, retirando de circulação cautelarmente, por meio de um procedimento célere, um medicamento que se venha afigurando nocivo à coletividade, sob pena de, não atuando de tal maneira, os danos eventualmente causados se tornarem irreversíveis.

Em contraposição, o cancelamento do registro configura-se um instrumento mais drástico, que vem a ser consumado somente no caso da comprovação da nocividade de certo medicamento no seio da sociedade, depois de transcorrida uma fase processual em que ambas as partes, autoridade coatora e administrado, tenham se munido dos princípios do devido processo legal nas defesas de seus interesses.

Outrossim, claro ficou que o tratamento ao tema dispensado pelo legislador foi de grande acuidade. Demonstrou-se perspicaz o suficiente para, ao mesmo tempo em que conseguiu proteger o interesse primário de uma sociedade que demanda um sistema de saúde de qualidade, não olvidou que do outro lado da relação material havia o fornecedor, o fabricante de medicamentos e produtos e o prestador de serviços de saúde que também agem no intuito de proteger seus interesses (econômicos ou quaisquer outros), garantidos, em caso de controvérsia judicial, pelos princípios do contraditório e da ampla defesa no delinear de um devido processo legal.

Desse modo, os limites de ambos os bens foram retraídos e, conseqüentemente, otimizados, atendendo, com o respaldo das palavras de Hesse, ao princípio de uma unidade da Constituição.

\section{BIBLIOGRAFIA}

ARANHA, Márcio lório; PICARELLI, Márcia Flávia Santini (orgs.). Política de patentes em saúde humana. São Paulo: Atlas, 2001.

DIAS, Hélio Pereira. Direito de Saúde. Rio de Janeiro: [s.n.], 1979.

[s.n.], 1988.

Teoria e prática do processo administrativo sanitário. Brasília:

GASPARINI, Diogenes. Direito Administrativo. $5^{\text {a }}$ ed. rev. atual. e ampl. São Paulo: Saraiva, 2000.

GOMES, Carolina et alii. Vigilância Sanitária de Medicamentos e Correlatos. $1^{\text {a }}$ ed. Rio de Janeiro: Quality Mark, [200-?].

SUNDFELD, Carlos Ari. Direito Administrativo Econômico. São Paulo: MaIheiros, 2000. 